\title{
A study on the microbiological quality of fresh noodles sold in Mauritius
}

\author{
Marie Sandy Tang Sik Fon, Dayawatee Goburdhun, Hudaa Neetoo* \\ Department of Agriculture and Food Science, Faculty of Agriculture, \\ University of Mauritius, Mauritius \\ Corresponding Author E-mail: s.neetoo@uom.ac.mu
}

\begin{abstract}
Noodles are a popular staple food and are consumed by all ethnic groups in Mauritius due to its convenience and palatability. The aim of this study was to evaluate the microbiological safety and quality of fresh noodles sold in markets and supermarkets of Mauritius. Fresh noodles were collected from 2 markets and 2 supermarkets located either in the Capital City or a commercial town of Mauritius. Samples were microbiologically assayed for Total Plate Count (TPC), presumptive Escherichia coli (EC), presumptive Staphylococcus aureus (SA), Yeast and mold count (YMC), Lactic acid bacteria, Pseudomonas spp., Bacillus cereus (BC) and Salmonella using official methods of analysis. Noodles purchased from all retail outlets were found to be unacceptable for sale as the level of TPC and SA exceeded the limits imposed by microbiological standards. There was also no significant difference $(P>0.05)$ in the microbial load of noodles between the different retail outlet types. The relatively high levels of spoilage microorganisms Pseudomonas spp. and Lactic Acid Bacteria suggest that the fresh noodles are highly perishable and have a very short shelf-life.
\end{abstract}

Keywords: Yellow alkaline noodles, fresh noodles, pathogens, spoilage bacteria.

\section{INTRODUCTION}

Noodles, an Asian stable food, have existed for thousands of years and are now consumed throughout the world. They are often confused with pasta, which is made with Triticum durum while noodles are made with Triticum aestivum (Houet al., 2010). Noodles are made with wheat flour, water and salt. The two main types of noodles are white salted noodles (WSN) and yellow alkaline noodles (YAN). YAN originated from the Canton and Hokkien provinces of China. In Mauritius, YAN is the sole commercially available fresh noodles and thought to have been brought by the Chinese immigrants in the late 1800s (GOM, 2013; Bolton et al., 2011). The alkaline salts added to the dough mixture impart a yellow colour and also gives the dough its elastic and extensible properties. Although the alkaline salts exhibit a weak antifungal property, our tropical climate makes YAN prone to spoilage.

Fresh noodles are sold in open markets, convenience stores or supermarkets and are displayed at room or refrigeration temperature depending on the retail outlet in question. According to Heerah (2005), the shelf-life of YAN in Mauritius varies from 3-7 days. Currently, there is little information on the microbial flora of YAN in the literature. This study aims at identifying the spoilage and pathogenic microorganisms of concern in commercially available YAN from different retail outlets in Mauritius.

\section{MATERIALS AND METHODS}

Samples were bought from markets (M) and supermarkets (SP) located either in the Capital City (M1 and SP1) or Central Town (M2 and SP2) of Mauritius. Samples were transported in a cooler box to the laboratory and analysed on the same day. A 25-g sample was homogenized with $225 \mathrm{ml}$ of $1 \%$ buffered peptone water in a stomacher bag for two minutes using a stomacher. Serial dilutions were prepared using $0.1 \%$ buffered peptone water and $100 \mu \mathrm{l}$ of appropriate dilutions were inoculated onto the agar in duplicates. Testing was conducted for Total Plate Count (TPC), presumptive Escherichia coli (EC), presumptive Staphylococcus aureus (SA), Yeast and mold count (YMC), Lactic acid bacteria, Pseudomonas spp. and Bacillus cereus (BC) by spread-plating or pour-plating on Plate Count agar (Oxoid), Eosin Methylene Blue agar (Oxoid), Baird Parker agar (Hi-Media), Dichloran Rose Bengal agar (Oxoid), De Man Rogosa Sharpe agar (Hi- 
Table 1. Microbiological criteria for noodle and pasta products

\begin{tabular}{|c|c|c|c|c|c|c|}
\hline \multirow[t]{2}{*}{ Microorganisms } & & \multicolumn{2}{|c|}{ NZMoH } & \multicolumn{2}{|c|}{ IFST } \\
\hline & $\mathbf{N}$ & $\mathbf{C}$ & $\mathbf{m}$ & $\mathbf{M}$ & $\mathbf{m}$ & $\bar{M}$ \\
\hline Aerobic plate count at 35 (cfu /g) & 5 & 2 & $10^{5}$ & $10^{6}$ & & \\
\hline Lactic acid bacteria (cfu /g) & 5 & 2 & & & $10^{4}$ & $10^{\prime}$ \\
\hline Coagulase producing Staphylococcus (cfu /g) & 5 & 2 & & & $10^{2}$ & $10^{4}$ \\
\hline Faecal coliform (cfu /g) & 5 & 2 & & & $10^{2}$ & $10^{4}$ \\
\hline Bacillus cereus (cfu /g) & 5 & 2 & & & $10^{2}$ & $10^{4}$ \\
\hline Salmonella (Absence in $25 \mathrm{~g}$ ) & 5 & 0 & $\mathrm{~m}=0$ & & & \\
\hline
\end{tabular}

(Adapted from NZMoH 1995; IFST 1997)

Table 2. Results of microbiological analysis of noodles bought from supermarket SP1

\begin{tabular}{|c|c|c|c|c|c|c|c|c|c|c|}
\hline \multirow{2}{*}{ Parameters } & \multicolumn{5}{|c|}{ Sampling Round 1} & \multicolumn{5}{|c|}{ Sampling Round 2} \\
\hline & A & B & C & D & E & A & B & C & D & E \\
\hline TPC (cfu/g) & $9.5 \times 10^{3}$ & $1.7 \times 10^{4}$ & $2.0 \times 10^{4}$ & $8.4 \times 10^{5}$ & $3.9 \times 10^{4}$ & $2.2 \times 10^{5}$ & $2.1 \times 10^{5}$ & $3.0 \times 10^{5}$ & $1.5 \times 10^{6}$ & $9.7 \times 10^{6}$ \\
\hline E. coli (cfu/g) & $<100$ & $<100$ & $<100$ & $<100$ & $<100$ & $<100$ & $<100$ & $<100$ & $<100$ & $<100$ \\
\hline YMC (cfu/g) & $4.0 \times 10$ & $1.0 \times 10^{2}$ & $3.0 \times 10$ & $5.5 \times 10^{2}$ & $5.0 \times 10$ & $4.0 \times 10$ & $8.4 \times 10^{2}$ & $1.4 \times 10^{2}$ & $1.0 \times 10^{3}$ & $5.1 \times 10^{2}$ \\
\hline S. aureus (cfu/g) & $3.0 \times 10^{3}$ & $3.5 \times 10^{3}$ & $<100$ & $2.4 \times 10^{6}$ & $1.7 \times 10^{4}$ & $8.5 \times 10^{3}$ & $5.5 \times 10^{3}$ & $3.5 \times 10^{4}$ & $6.4 \times 10^{5}$ & $7.3 \times 10^{5}$ \\
\hline LAB (cfu/g) & $5.0 \times 10$ & $1.9 \times 10^{2}$ & $1.5 \times 10^{2}$ & $5.2 \times 10^{3}$ & $6.2 \times 10^{2}$ & $4.1 \times 10^{2}$ & $3.5 \times 10^{2}$ & $7.9 \times 10^{2}$ & $4.1 \times 10^{3}$ & $7.3 \times 10^{3}$ \\
\hline Pseudomonas spp. (cfu/g) & $<100$ & $<100$ & $<100$ & $<100$ & $<100$ & $7.0 \times 10$ & $5.0 \times 10$ & $1.0 \times 10$ & $1.5 \times 10^{2}$ & $3.4 \times 10^{2}$ \\
\hline B. cereus $(\mathrm{cfu} / \mathrm{g})$ & $<100$ & $<100$ & $<100$ & $<100$ & $<100$ & $<100$ & $<100$ & $<100$ & $<100$ & $<100$ \\
\hline Salmonella (/25 g) & - & - & - & - & - & - & - & - & - & - \\
\hline
\end{tabular}

-/+: Number of samples testing positive out of five

Media), Pseudomonas agar (Hi-Media) and Mannitol Yolk Polymyxin agar (Oxoid) respectively. Salmonella was tested using the FDA BAM (2001) method and presence (+) or absence (-) of Salmonella was noted. PCA plates were incubated at $30^{\circ} \mathrm{C}$ for $72 \mathrm{hr}$ while all other plates were incubated at $25^{\circ} \mathrm{C}$ for $48 \mathrm{hr}$. The colonies were counted using a colony counter.

Data obtained was computed using Microsoft
Excel 2007 and analysed using Minitab Inc. 17. The results obtained were compared with relevant microbiological standards of the New Zealand Ministry of Health (1995) and IFST (1997) for pasta and noodles (Table 1) to determine the acceptability of the fresh noodles.

The population density for each microbiological parameter was log-transformed and significant differences in the microbial counts of samples between markets and supermarkets was analysed using Analysis of Variance (ANOVA) and differences determined at the 95\% confidence level $(\alpha=0.05)$ using the Tukey test.

\section{RESULTS AND DISCUSSION}

Two visits were made at each of the four retail outlets and at each visit, 5 samples of noodles 
Table 3. Results of microbiological analysis of noodles bought from supermarket SP2

\begin{tabular}{|c|c|c|c|c|c|c|c|c|c|c|}
\hline \multirow[t]{2}{*}{ Parameters } & \multicolumn{5}{|c|}{ Sampling Round 1} & \multicolumn{5}{|c|}{ Sampling Round 2} \\
\hline & A & B & C & D & $\mathbf{E}$ & $\mathbf{A}$ & B & C & D & $E$ \\
\hline TPC (cfu/g) & $3.4 \times 10^{5}$ & $5.7 \times 10^{5}$ & $1.2 \times 10^{6}$ & $2.3 \times 10^{6}$ & $1.9 \times 10^{6}$ & $7.2 \times 10^{5}$ & $6.9 \times 10^{5}$ & $5.6 \times 10^{5}$ & $8.0 \times 10^{5}$ & $7.6 \times 10^{5}$ \\
\hline E. coli $(\mathrm{cfu} / \mathrm{g})$ & $<100$ & $1.1 \times 10^{3}$ & $<100$ & $3.8 \times 10^{2}$ & $4.4 \times 10^{2}$ & $1.3 \times 10^{3}$ & $1.2 \times 10^{3}$ & $2.0 \times 10^{3}$ & $2.3 \times 10^{3}$ & $1.9 \times 10^{3}$ \\
\hline YMC (cfu/g) & $6.0 \times 10$ & $3.0 \times 10^{2}$ & $1.1 \times 10^{2}$ & $7.0 \times 10$ & $4.0 \times 10$ & $5.0 \times 10$ & $4.0 \times 10$ & $9.0 \times 10$ & $1.0 \times 10^{2}$ & $3.2 \times 10^{2}$ \\
\hline S. aureus (cfu/g) & $8.6 \times 10^{4}$ & $1.1 \times 10^{6}$ & $6.1 \times 10^{5}$ & $2.0 \times 10^{6}$ & $5.7 \times 10^{5}$ & $1.6 \times 10^{5}$ & $1.5 \times 10^{5}$ & $1.2 \times 10^{5}$ & $4.1 \times 10^{5}$ & $4.3 \times 10^{5}$ \\
\hline LAB $(\mathrm{cfu} / \mathrm{g})$ & $4.9 \times 10^{2}$ & $1.6 \times 10^{4}$ & $6.9 \times 10^{3}$ & $1.3 \times 10^{4}$ & $4.8 \times 10^{3}$ & $2.3 \times 10^{3}$ & $6.8 \times 10^{3}$ & $3.6 \times 10^{3}$ & $6.8 \times 10^{3}$ & $3.9 \times 10^{3}$ \\
\hline Pseudomonas spp (cfu/g) & $<100$ & $<100$ & $<100$ & $<100$ & $<100$ & $<100$ & $<100$ & $<100$ & $<100$ & $<100$ \\
\hline B. cereus $(\mathrm{cfu} / \mathrm{g})$ & $<100$ & $<100$ & $<100$ & $<100$ & $<100$ & $<100$ & $<100$ & $<100$ & $<100$ & $<100$ \\
\hline Salmonella (/25 g) & - & - & - & - & - & - & - & - & - & - \\
\hline
\end{tabular}

$-/+$ : Number of samples testing positive out of five

Table 4. Results of microbiological analysis of noodles bought from market M1

\begin{tabular}{|c|c|c|c|c|c|c|c|c|c|c|}
\hline \multirow[t]{2}{*}{ Parameters } & \multicolumn{5}{|c|}{ Sampling Round 1} & \multicolumn{5}{|c|}{ Sampling Round 2} \\
\hline & A & B & C & D & E & A & B & C & D & E \\
\hline TPC (cfu/g) & $4.2 \times 10^{5}$ & $1.7 \times 10^{6}$ & $2.1 \times 10^{5}$ & $4.2 \times 10^{4}$ & $1.7 \times 10^{4}$ & $1.5 \times 10^{5}$ & $2.2 \times 10^{5}$ & $2.3 \times 10^{5}$ & $1.8 \times 10^{5}$ & $2.0 \times 10^{5}$ \\
\hline E. coli $(\mathrm{cfu} / \mathrm{g})$ & $<100$ & $<100$ & $<100$ & $<100$ & $<100$ & $<100$ & $<100$ & $<100$ & $<100$ & $<100$ \\
\hline YMC (cfu/g) & $3.0 \times 10$ & $6.0 \times 10$ & $3.0 \times 10$ & $3.0 \times 10$ & $2.0 \times 10$ & $5.0 \times 10$ & $4.0 \times 10$ & $4.0 \times 10$ & $2.0 \times 10$ & $1.0 \times 10$ \\
\hline S. aureus (cfu/g) & $7.5 \times 10^{4}$ & $1.6 \times 10^{6}$ & $1.6 \times 10^{5}$ & $4.8 \times 10^{4}$ & $4.5 \times 10^{4}$ & $5.3 \times 10^{6}$ & $2.8 \times 10^{6}$ & $1.1 \times 10^{6}$ & $9.1 \times 10^{5}$ & $1.0 \times 10^{6}$ \\
\hline LAB $(\mathrm{cfu} / \mathrm{g})$ & $8.0 \times 10$ & $4.0 \times 10$ & $9.0 \times 10$ & $1.5 \times 10^{2}$ & $4.0 \times 10$ & $2.2 \times 10^{2}$ & $5.9 \times 10^{2}$ & $4.0 \times 10$ & $5.0 \times 10$ & $7.0 \times 10$ \\
\hline Pseudomonas (cfu/g) & $<100$ & $<100$ & $<100$ & $<100$ & $<100$ & $<100$ & $<100$ & $<100$ & $<100$ & $<100$ \\
\hline B. cereus $(\mathrm{cfu} / \mathrm{g})$ & $<100$ & $<100$ & $<100$ & $<100$ & $<100$ & $<100$ & $<100$ & $<100$ & $<100$ & $<100$ \\
\hline Salmonella (/25 g) & - & - & - & - & + & - & - & - & - & - \\
\hline
\end{tabular}

$-/+$ : Number of samples testing positive out of five

were purchased totalling 40 noodle samples. The test results for the various microbiological parameters for each sample purchased following each sampling round is presented in Tables 2-5. TPC of samples ranged from $2.0 \times 10^{3}-9.7 \times 10^{6}$ cfu/g. $50 \%$ of noodle samples from the market and supermarket from the central town (i.e. M2 and SP2) harbored presumptive $E$. coli at population densities varying from $2 \times 10^{1}-2.3 \times 10^{3}$ cfu/g. Rockliff et al. (1997) also noted approximately the same level of $E$. coli in fresh par-boiled noodles. YMC were present at varying levels of $1 \times 10^{1}-3.7 \times 10^{3} \mathrm{cfu} / \mathrm{g}$ respectively. $95 \%$ of the samples were found to harbour presumptive SA and the highest count was $2.4 \times 10^{6} \mathrm{cfu} / \mathrm{g}$. Pseudomonas spp. was identified in samples purchased from SP1 and M2 only, with a maximum count of $3.4 \times 10^{2} \mathrm{cfu} / \mathrm{g}$. Lactic acid 
Table 5. Results of microbiological analysis of noodles bought from market M2

\begin{tabular}{|c|c|c|c|c|c|c|c|c|c|c|}
\hline \multirow{2}{*}{ Parameters } & \multicolumn{5}{|c|}{ Sampling Round 1} & \multicolumn{5}{|c|}{ Sampling Round 2} \\
\hline & A & B & C & D & E & A & B & C & D & E \\
\hline TPC (cfu/g) & $3.0 \times 10^{4}$ & $1.5 \times 10^{4}$ & $7.5 \times 10^{3}$ & $4.0 \times 10^{3}$ & $2.2 \times 10^{4}$ & $2.0 \times 10^{3}$ & $2.5 \times 10^{5}$ & $8.5 \times 10^{4}$ & $3.5 \times 10^{3}$ & $4.5 \times 10^{3}$ \\
\hline E. coli (cfu/g) & $8.0 \times 10$ & $4.0 \times 10$ & $9.0 \times 10$ & $8.0 \times 10$ & $4.0 \times 10^{2}$ & $2.0 \times 10$ & $3.8 \times 10^{2}$ & $3.0 \times 10$ & $5.0 \times 10$ & $2.0 \times 10$ \\
\hline YMC (cfu/g) & $1.2 \times 10^{3}$ & $1.1 \times 10^{3}$ & $3.6 \times 10^{2}$ & $4.0 \times 10$ & $7.3 \times 10^{2}$ & $8.0 \times 10$ & $3.7 \times 10^{3}$ & $4.6 \times 10^{2}$ & $1.1 \times 10^{3}$ & $5.7 \times 10^{2}$ \\
\hline S. aureus (cfu/g) & $3.0 \times 10^{3}$ & $<100$ & $3.5 \times 10^{3}$ & $2.5 \times 10^{3}$ & $2.0 \times 10^{3}$ & $1.0 \times 10^{3}$ & $7.1 \times 10^{5}$ & $1.0 \times 10^{3}$ & $3.5 \times 10^{3}$ & $4.0 \times 10^{3}$ \\
\hline LAB (cfu/g) & $2.2 \times 10^{3}$ & $1.7 \times 10^{3}$ & $1.3 \times 10^{3}$ & $7.5 \times 10^{2}$ & $1.3 \times 10^{3}$ & $1.3 \times 10^{2}$ & $5.9 \times 10^{3}$ & $3.0 \times 10^{2}$ & $7.9 \times 10^{2}$ & $5.2 \times 10^{2}$ \\
\hline Pseudomonas (cfu/g) & $2.1 \times 10^{2}$ & $<100$ & $1.1 \times 10^{2}$ & $1.0 \times 10^{2}$ & $1.7 \times 10^{2}$ & $1.0 \times 10^{2}$ & $2.0 \times 10^{2}$ & $<100$ & $<100$ & $4.0 \times 10$ \\
\hline B. cereus $(\mathrm{cfu} / \mathrm{g})$ & $<100$ & $<100$ & $<100$ & $<100$ & $<100$ & $<100$ & $<100$ & $<100$ & $<100$ & $<100$ \\
\hline Salmonella (/25 g) & - & - & - & - & - & - & - & - & - & - \\
\hline
\end{tabular}

$-/+$ : Number of samples testing positive out of five

Table 6. Decision outcomes following analyses at four retail outlets

\begin{tabular}{lcccc}
\hline & \multicolumn{2}{c}{ Supermarket } & \multicolumn{2}{c}{ Market } \\
\cline { 2 - 5 } & SP1 & SP2 & M1 & M2 \\
\hline $1^{\text {st }}$ Sampling Round & Unacceptable & Unacceptable & Unacceptable & Unacceptable \\
\hline $2^{\text {nd }}$ Sampling Round & Unacceptable & Unacceptable & Unacceptable & Unacceptable \\
\hline
\end{tabular}

bacteria were found at densities ranging from $4 \times 10^{1}$ to $1.6 \times 10^{4} \mathrm{cfu} / \mathrm{g}$. BC was undetectable by the plating methodology (<100 cfu/g). Salmonella was detected in only one out of the five samples purchased from Market M1 and none in the remaining samples. Heerah (2005) and Jensen et al. (2002), on the hand, reported Salmonella to be undetectable in samples of commercially available noodles. The low prevalence of Salmonella noted in our study may have arisen by crosscontamination through food handlers who inadequately washed their hands after using the toilet. Indeed, enteric pathogen Salmonella Typhi forms part of the human bowels flora, especially of asymptomatic carriers.

Based on the microbiological criteria shown in Table 1, the batch of samples purchased from the 4 retail outlets were deemed microbiologically unsafe and unfit for consumption as the counts of both TPC and SA exceeded the microbiological limits. According to the NZMoH (1995), for a lot of product to be considered acceptable for sale and safe for consumption, not more than two out of five samples should have counts of mesophilic aerobes falling in the range of $10^{5}-10^{6} \mathrm{cfu} / \mathrm{g}$. Samples bought from M2 during the $1^{\text {st }}$ sampling round did not exceed the microbiological criteria for TPC, although they had exceeded the $M$ value of $10^{2} \mathrm{cfu} / \mathrm{g}$ for SA (IFST, 1997). A summary of the decision outcomes with respect to the acceptability of the lots of noodles sold at the different retail outlets is provided in Table 6 .

Table 7 compares the average population densities of noodle samples sold at markets vs. supermarkets for each microbiological parameter tested. There was no significant difference in the counts of TPC, presumptive SA, YMC and LAB between noodles purchased at supermarkets vs. markets within the same location. Moreover, there was also no significant difference in the TPC of noodles between the two markets 
Marie et al. 129

Table 7. Microbial profile of noodles sourced from the four retail outlets.

\begin{tabular}{lcccc}
\hline & \multicolumn{2}{c}{ Supermarkets } & \multicolumn{2}{c}{ Markets } \\
& SP1 & SP2 & M1 & M2 \\
\cline { 2 - 5 } TPC (Log cfu/g) & $5.3 \pm 0.9^{\mathrm{a}}$ & $5.9 \pm 0.1^{\mathrm{a}}$ & $5.5 \pm 0.3^{\mathrm{a}}$ & $4.1 \pm 0.1^{\mathrm{a}}$ \\
E. coli (Log cfu/g) & $<2$ & $3.0 \pm 0.3^{\mathrm{a}}$ & $<2$ & $1.9 \pm 0.2^{\mathrm{b}}$ \\
YMC (Log cfu/g) & $2.2 \pm 0.4^{\mathrm{ab}}$ & $2.0 \pm 0.1^{\mathrm{ab}}$ & $1.5 \pm 0.0^{\mathrm{b}}$ & $2.7 \pm 0.1^{\mathrm{a}}$ \\
S. aureus (Log cfu/g) & $4.6 \pm 0.3^{\mathrm{ab}}$ & $5.6 \pm 0.3^{\mathrm{a}}$ & $5.7 \pm 0.8^{\mathrm{a}}$ & $3.6 \pm 0.3^{\mathrm{b}}$ \\
LAB (Log cfu/g) & $2.8 \pm 0.4^{\mathrm{ab}}$ & $3.7 \pm 0.1^{\mathrm{a}}$ & $2.1 \pm 0.3^{\mathrm{b}}$ & $3.0 \pm 0.2^{\mathrm{ab}}$ \\
Pseudomonas (Log cfu/g) & $<2$ & $<2$ & $<2$ & $2.1 \pm 0.1$ \\
B. cereus (Log cfu/g) & $<2$ & $<2$ & $<2$ & $<2$ \\
Salmonella (n/5)* & $0 / 5,0 / 5$ & $0 / 5,0 / 5$ & $0 / 5,1 / 5$ & $0 / 5,0 / 5$ \\
\hline
\end{tabular}

Means within the same row followed by common superscripts letters are not significantly different $(P>0.05)$ $(\mathrm{n} / 5)^{\star}$ : Number of samples testing positive for Salmonella out of five

$(P>0.05)$. Similarly, there was no significant difference in the TPC of noodles between the two supermarkets ( $P$ $>0.05)$ although differences in counts of presumptive SA $(\Delta=2.1 \log \mathrm{cfu} / \mathrm{g})$ and $\mathrm{YMC}(\Delta=1.2 \mathrm{log} \mathrm{cfu} / \mathrm{g})$ were statistically significant. This implies that the type and location of retail outlets did not have an appreciable impact on the microbial quality of noodles.

TPC of alkaline noodles ranging from 4.1-5.9 log cfu/g as noted in our study are in fact in close agreement with population density of ca. $5 \mathrm{log} \mathrm{cfu} / \mathrm{g}$ reported by Jensen et al. (2002), Millard (2008), and Ghaffar et al. (2009). The high TPC, usually indicative of overall poor sanitary quality, could be partly accounted for by poor cleaning practices of manufacturers who superficially scraped the excess dough off the equipment surfaces. Indeed, residues built up in the processing equipment's may contribute to significant source of contamination (Ghaffar et al., 2009). According to Rosyid et al. (2011), the pH of 9-11 of alkaline noodles may further enhance the development of bacteria and fungi, imparting a slimy characteristic to the noodles. Food is considered spoiled when TPC exceeds $10^{6} \mathrm{cfu} / \mathrm{g}$ (Spinelli, 2000). Noodle samples analysed in this study were freshly produced earlier on the same day and yet their TPC counts were as high as ca. $5 \mathrm{log} \mathrm{cfu} / \mathrm{g}$ after a few hours of production, thus suggesting the perishable nature of noodles. Lee et al. (2008) and Fu $(2000 ; 2008)$ concluded that alkaline noodles have a shelf-life of 2 to a few days only, which is in fact shorter than the nominal shelf-life displayed on the package of noodles purchased at the retail outlets.

The highest level of presumptive SA was of the order of $4 \mathrm{log} \mathrm{cfu} / \mathrm{g}$ and this may be attributed to the extensive manual manipulation by the manufacturers during the packing step. Heerah (2005) reported the recovery of Staphylococcus epidermidis, from commercially available noodles in Mauritius. Forsythe (2010) stated that since almost $40 \%$ of humans in general are asymptomatic carriers of Staphylococcus spp., it is not practical to exclude carriers in food production areas and eliminate Staphylococcus in food receiving extensive handling. Therefore, preventive measures such as proper hand washing and use of disposable gloves may reduce its prevalence in food. Pseudomonas spp. are regarded as spoilage indicators and also represent the natural flora of wheat flour (Mayou and Moberg, 1992). However, no studies to date have investigated the occurrence of Pseudomonas spp. in noodles. While YMC from noodle samples ranged from 1 to $3 \mathrm{log} \mathrm{cfu} / \mathrm{g}$, higher counts of 5 log cfu/g was reported by Jensen et al. (2002). LAB were detected in all samples with a maximum level of $4.1 \mathrm{log}$ $\mathrm{cfu} / \mathrm{g}$ however, the levels did not exceed the maximum level (IFST, 1997). BC was not detected in any of the products. Berghofer et al. (2003) reported that milled flour contained less than one spore per gram while Rockliff et al. (1997) did observe BC at a variable population density ranging from 1-3 log cfu/g in noodles and other starch products.

\section{CONCLUSION}

The high levels of background flora in yellow alkaline noodles suggest that this product is highly perishable and is susceptible to rapid spoilage. There was no significant difference in the microbiological quality of noodle samples displayed in open-air markets or in closed refrigerated sections of supermarkets. In the light of the microbiological results, it is recommended that consumers do not store fresh noodles for more than 2 days and that cooking be effected adequately to ensure that all pathogenic bacteria are eliminated. Future studies should aim to establish the shelf-life of commercially available noodles in Mauritius. Moreover, microbiological standards for fresh noodles should be best abolished by the local authority and be included in our local regulations.

\section{REFERENCES}

[Accessed on 5 September 2013]

Bolton WD(2011). The history of Mauritius: British perspectives. P. Ramsurrun, (Ed.), Mauritius: Mata Soondree Publishers Limited. pp. 174.

Food and Drug Administration Bacteriological Analytical Manual, Chapter 5,Salmonella May 2014 Version.

Forsythe SJ(2010). Themicrobiologyofsafe food.WileyBlackwell.Second edition. 
Fu BX(2008). Asian noodles: History, classification, raw materials, and processing. Food Res. Int. 41: 888.

Fu XR(2000). Fresh wet rice noodle and processing technology. (In Chinese) Food Ind. 5:9,

Ghaffar S, Abdulamir AS, Abu Bakar F, Karim R, Saari N(2009). Microbial Growth, Sensory Characteristic and $\mathrm{pH}$ as Potential Spoilage Indicators of Chinese Yellow Wet Noodles from Commercial Processing Plants.American Journal of Applied Sciences 6 (6): 1059-1066, 2009.

Government of Mauritius, 2013. Mauritian Cuisine [online]. Available from:

http://www.gov.mu/English/ExploreMauritius/Culture/Pages/Culture/ Mauritian-Cuisine.aspx [Accessed on 14 February 2014]

Heerah RK(2005). Food borne pathogens in commercially available noodles. Dip.Thesis, University of Mauritius.

Hou GG(Ed.), 2010. Asian noodles: science, technology, and processing. John Wiley \& Sons. New Jersey.

Institute of Food Science and Technology (IFST), 1997. Development and use of microbiologicalcriteria for foods. Food Science and TechnologyToday, 11 (3), 160.

Jensen N, Kocking A, Miskelly D, Berghofer L(2002). Market place survey of the microbiological status of noodles sold in Australia [online]. Value Added Wheat CRC Report Available from: http://ses.library.usyd.edu.au/bitstream/2123/2703/1/VAWCRC\%20 Report\%2015.pdf
Lee S, Bae IY, Jung JH, Hyeon GL(2008). Physicochemical, textural and noodle-making properties of wheat dough containing alginate.39(4):393 - 404. Journal of Texture Studies.

Millard G(2008). Microbiological quality of noodles. ActHealth Protection Service Report.

New Zealand Ministry of Health, 1995. Food Administration Manual: Microbiological criteria [online]. pp 25. Available from: http://www.foodsafety.govt.nz/elibrary/industry/microbiological_refer ence-guide assess.pdf [Accessed on 16 June 2016]

Rockliff S, Rigg A, Millard G(1997). Microbial quality and preservatives in fresh pasta and noodles.Food survey report, Act Health.

Rosyid TA, Karim R, Adzahan NM, Chazali FM(2011). Antibacterial activity of several Malaysian leaves extracts on the spoilage bacteria of yellow alkaline noodles. African Journal of Microbiology Research, 5 (8), 898- 904.

Spinelli $\mathrm{J}(2000)$. Consumer Acceptance. Factor relating to finfish flavour, odour and quality changes. In: R.E. Martin, E. Paine Carter, G. J. Flick, and L.M. Davis. Eds. Marine and freshwater products handbook. USA: Technomic Publishing Company. pp 827. 